Maria Sonnenberg*, René Gustus, Sascha Sedelmeier, Lienhard Wegewitz, Oliver Höfft, Jürgen Wieser and Wolfgang Maus-Friedrichs

\title{
Polymer-induced metal diffusion during plastic processing: a reason for deposit formation
}

https://doi.org/10.1515/polyeng-2018-0324

Received October 22, 2018; accepted February 17, 2019; previously published online April 4, 2019

Abstract: In the plastic-processing industry, the formation of unknown deposits at the interface between polymer melt and steel surfaces can pose major challenges, which occurs especially on screws, barrels, and tools. These deposits will detach during production and lead to quality restrictions mostly as spots in the products. We investigated the interactions between tool steel and polymer melt, especially polycarbonate, in the early stages of deposit formation. Steel-polymer-composite samples are prepared close to the realistic conditions in the plasticprocessing industry. To get further insight, thin polymer films on tool steel specimens and its alloy elements, representing model systems, are prepared. X-ray-photoelectron spectroscopy (XPS) and Auger electron spectroscopy (AES) are used to characterize the interfaces chemically. Additionally, atomic force microscopy (AFM) and scanning electron microscopy (SEM) were used. We found iron and chromium diffusion into the polycarbonate melt induced by polymer metal interaction. Iron and polymer chains are immobilized at the interface by a chemical interaction, while chromium does not chemically interact with the polymer melt. Basing on these results, we propose a mechanism for deposit formation in plastic-processing machines and tools.

\footnotetext{
*Corresponding author: Maria Sonnenberg, Clausthal Centre of Material Technology, Clausthal University of Technology, Agricolastraße 2, 38678 Clausthal-Zellerfeld, Germany, e-mail: maria.sonnenberg@tu-clausthal.de. https://orcid.org/0000-0002-4843-6511 René Gustus, Lienhard Wegewitz and Wolfgang Maus-Friedrichs: Clausthal Centre of Material Technology, Clausthal University of Technology, Agricolastraße 2, 38678 Clausthal-Zellerfeld, Germany Sascha Sedelmeier: Fraunhofer Institute for Structural Durability and System Reliability LBF, Schlossgartenstraße 6, 64289 Darmstadt, Germany Oliver Höfft: Institute for Electrochemistry, Clausthal University of Technology, Arnold-Sommerfeld Straße 6, 37678 ClausthalZellerfeld, Germany

Jürgen Wieser: Department of Mechanical and Plastics Engineering, University of Applied Sciences, Haardtring 100, 64295 Darmstadt, Germany
}

Keywords: metal ion diffusion; metal-polymer interaction; mold fouling; plate-out formation; polymer processing.

\section{Introduction}

The formation of unknown deposits at the steel surfaces of plastic-processing machines and tools is a major challenge in industrial production processes [1]. Parts of those deposits will detach during production and lead to quality restrictions, mostly as spots in the products. In practice, those problems are often reduced by steel surface coatings, which prevent any contact between steel and polymer melt [2, 3]. However, up to now, the reliability of these coatings in preventing plate-out is not sufficient. A complete understanding of the deposit formation mechanisms and the processes occurring in the early stages of the interaction between steel surface and polymer melt has not been developed yet.

Several research groups are dealing with investigations on metal-polymer interfaces. Mostly, evaporated metal ions were deposited on polymer layers, which were heated afterward. The metal diffusion and interaction were analyzed by different surface analytical methods, e.g. X-ray photoelectron spectroscopy (XPS), transmission electron microscopy (TEM), Fourier-transform infrared spectroscopy (FTIR), or atomic force microscopy (AFM) [4-9].

Faupel et al. studied metal ion diffusion from thin metal films into polymer melt. They prepared thin layers of $\mathrm{Cr}$, Ni, $\mathrm{Cu}$, and Ti on polyimide and Teflon substrates, respectively. The results prove the diffusion of the more noble metal ions $\mathrm{Ag}, \mathrm{Au}$, and $\mathrm{Cu}$ into thin polyimide layers, while less noble metal ions $\mathrm{Cr}$, Ti, and Ce did not show any diffusion [4]. The correlations between temperature and diffusion process of metal ions were analyzed by Bechtolsheim et al. and Faupel et al. Both working groups exposed temperature as an important force for the diffusion of the metal ions into the polymer substrate $[5,10]$. Basic investigations on the chemical interactions between metal ions and polymer substrates were done by James Burkstrand [6]. Thin layers of $\mathrm{Cr}$, Ni, and $\mathrm{Cu}$ were prepared on polystyrene and polyvinyl-alcohol, and the samples were heated beyond their glass transition temperature. The XPS data reveal a polymer-metal 
complexation as the main reason for the strong bonding between the thin metal film and the polymer substrate [6]. Furthermore, Burkstrand prepared polystyrene layers, which were treated by an oxygen plasma. After the plasma treatment process, copper ions were deposited at the polymer surface. This results in the formation of a metaloxygen-polymer bonding. It was pointed out that a high oxygen concentration at the surface of the polymer leads to a stronger bonding and an intense complexation $[7,8]$. Related to Burkstrands results, Lee et al. analyzed the interface between $\mathrm{Cu}$ and polyimide. They pointed out a strong bonding between metal and polymer via nitrogen atoms [9].

The influence of a metal-polymer interface on degradation mechanism and temperature has also been investigated by various working groups [11-14]. Degradation by metal ions can support thermal degradation. In addition, degradation induced by metal ions can lead to the formation of polymer-metal compounds and influence crosslinking [12, 15, 13].

The referred working groups prepared samples of thin metal layers on polymers by metal evaporation. There are few working groups dealing with the direct contact of a solid metal surface with a polymer melt.

Gundjian and Fisa investigated composite materials made of aluminum-polyamide-aluminum or copper-polyamide-copper [16]. A metal diffusion into the polymer layer could be detected by XPS. Grundjian et al. suspected an interaction between the carbonyl group of the polyamide and the metal ions. Kalnins and Malers brought polyolefins into contact with steel surface. They verified the diffusion of iron ions over several micrometers deep into the polymer layer using X-ray spectral fluorescence analysis [17]. Larrazabal et al. were able to confirm the results of Kalnins et al. [18].

Friedrich et al. prepared thin layers of chromium on polycarbonate. The XPS investigations showed the formation of pi complexes between the carbon atoms of the aromatic ring and the metal ions. In addition, the formation of a Cr-O-C bond in place of the carbonyl group could be demonstrated [13]. Interaction and degradation step are postulated by Wiesing et al. [15]. They used XPS, AFM, and UV/Vis to prove their assumptions. In fact, they describe the interaction of polycarbonate at the $\mathrm{Fe} / \mathrm{Fe}_{\mathrm{x}} \mathrm{O}_{\mathrm{y}}$ interface. Based on this interaction of molten polycarbonate and Fe(II)-rich oxides, Fe(II)-enriched complexes are formed. The organic
Fe(II)-rich complexes can influence the thermal degradation of polycarbonate and leads to crosslinking.

We studied the interface between steel and the components of steel and polycarbonate. In contrast to Wiesing et al., we investigated the diffusion of iron ions into the polycarbonate layer. Furthermore, our investigations have the aim to explain the formation of deposits in plasticprocessing machines.

Polymer-steel composite samples were prepared in a hydrostatic press device at elevated temperatures to analyze adhesion behavior and to compare our model system with the real industrial process. Furthermore, we prepare thin polymer films on different metal surfaces. These thin polymer films on iron and chromium foils work as model systems. Thin polymer films on tool steel specimens act as a reference for real process surfaces in plasticprocessing machines. Surface analysis was done by XPS, Auger electron spectroscopy (AES), AFM, scanning electron microscopy (SEM), and light microscopy. We want to discuss whether new chemical compounds are formed at the interface between polymer and metal, which alloy elements take part in the polymer/metal interaction, and if metal diffusion into the polymer takes place.

\section{Materials and methods}

\subsection{Samples}

To investigate the interactions at metal-polymer interfaces, two different approaches were chosen:

1. Polymer-steel composite samples: To resemble industrial processes, polymer-steel composite samples were prepared. Polycarbonate (Makrolon 2407) was pressed between tool steel specimens (1.2379, Germany EN 10027) at a pressure of 150 bar and a temperature of $320^{\circ} \mathrm{C}$ for $15 \mathrm{~min}$. After cooling down, the polymersteel composite samples were separated mechanically, and the resulting interfaces were investigated by XPS (Omicron, Taunusstein, Germany, Veeco Instruments Inc., Santa Barbara, CA, USA) and AFM (Dimention TM 3100, Digital Instruments, Bresso, Italy). Figure 1 schematically shows the sample structure and the mechanically separated sample surfaces.

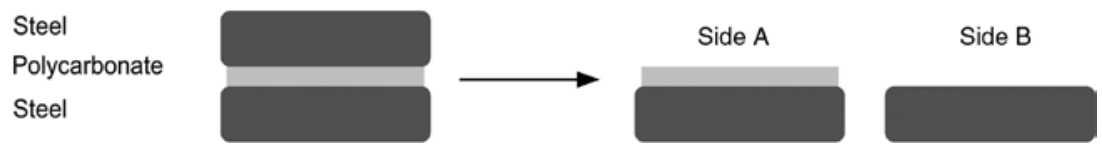

Figure 1: Polymer-steel composite sample prepared as described above. 
Surprisingly, the mechanical separation of these samples resulted in an adhesive failure, e.g. in two quite different pieces in almost every experiment. One of them contains a thick polymer layer (side A), while the other one appears optically to be free of polycarbonate (side B). However, we will show later that a thin polymer layer remained on side B in all cases.

2. Thin polymer films: Model systems of thin polymer films were prepared on tool steel specimens as well as on specimens of its alloy elements iron and chromium (Chromand iron-foil: MaTeck, Jülich, Germany). Polycarbonate (Makrolon 2408, Covestro, Leverkusen, Germany) was dissolved in 99\% dichloromethane (Sigma-Aldrich, Darmstadt, Germany). A predefined volume (300 $\mu \mathrm{l}$, polymer concentration $9 \times 10^{-2} \mathrm{~g} / \mathrm{l}$ ) of the prepared solution was dripped onto the different substrates. After the evaporation of the solvent, which took place at room temperature within $30 \mathrm{~s}$, a thin layer of polycarbonate remained on the surface. These thin polymer films were subsequently analyzed by XPS before the samples underwent heat treatments for $2 \mathrm{~h}$ at $280^{\circ} \mathrm{C}$ in ambient air. For this purpose, a muffle furnace from the company Nabertherm was used. Afterward, the interfaces were analyzed again by XPS, SEM, and AES.

\subsection{Analysis}

AFM measurements were performed using a Veeco Dimension 3100 SPM. All AFM images were recorded in tapping mode with a line-scan frequency of $0.5 \mathrm{~Hz}$. For image post-processing and analysis, SPIP (Image Metrology A/S, Lyngby, Denmark) was used.

XPS was carried out in an Ultra High Vacuum (UHV) apparatus with a base pressure of $1 \times 10^{-8} \mathrm{~Pa}$ (Omicron MULTIPROBE System). The samples were mounted on molybdenum sample plates and were transferred into the UHV apparatus by a multi-stage transfer system. XPS was performed with a non-monochromatic X-ray source (DAR 400, Omicron UHV Nanoprobe System, Taunusstein, Germany, Veeco Instruments Inc., Santa Barbara, CA, USA) using Al $\mathrm{K}_{\alpha}$ radiation $(1486.6 \mathrm{eV})$. The electrons emitting from the sample were analyzed using a hemispherical analyzer (EA 125 , Omicron), mounted at $45^{\circ}$ to the surface normal. Concerning the qualitative and quantitative analysis of the XPS spectra CasaXPS (Casa Software Ltd, Teigmouth, UK) and Origin7G (Origin Lab, Northampton, MA, USA) were used. Peak fitting was performed applying a Levenberg-Marquardt algorithm and a linear background subtraction (CasaXPS).

SEM and AES were carried out in an UHV apparatus with a base pressure of $1 \times 10^{-8} \mathrm{~Pa}$ (Omicron NANOPROBE
System, NanoSAM) with primary electrons produced by a UHV-Gemini column. Concerning the qualitative and quantitative analysis of the AES spectra EIS (electron and ion spectroscopy software) was used. For the analysis of SEM images, ISEM (imaging software for electron microscopy) was used.

\section{Results}

The interaction of polycarbonate melts with steel surfaces was investigated by means of polymer-steel composite samples as described in the experimental section. Figure 2 shows the results of microscopic and spectroscopic analysis for side B, which seems optically to be free of polymer.

Figure 2A shows the AFM image. Besides the typical scouring due to polishing and grinding of the steel surface (straight dark lines), a thin film is also visible, which contains dark, roundish spots. As dark regions in the AFM image are assigned to lower vertical positions on the surface, the dark spots represent holes. In AFM measurements carried out previously on the clean steel surface (not in contact with polycarbonate melt), such porous structures were not observed. Therefore, we conclude that the steel surface is covered by a thin porous film. The average film thickness, determined by measuring the high profile along the surface, reaches to $10 \pm 2 \mathrm{~nm}$.

In the XPS survey spectrum (Figure 2B), carbon (75\%) at binding energies of $285 \mathrm{eV}$ and oxygen (21\%) at 532.5 $\mathrm{eV}$ can be identified as the main components of the elemental composition. Besides carbon and oxygen, small amounts of iron (1\%) at $710 \mathrm{eV}$ as well as chlorine (1\%) and phosphorous $(2 \%)$ are present. The Markrolon was provided by the industry. The detected chlorine and phosphorus may be due to the addition of additives or possibly to reactants in the production of polycarbonate. The proportion is too low (1-2\%) to expect accumulation of additives on the surface. In the following XPS investigations, what the thin film on the steel surface consists of should be discussed. For a detailed chemical analysis, XPS detail measurements especially of the iron Fe2p and the carbon C1s orbital were performed. The XPS spectra of the Fe2p and the C1s orbitals are depicted in Figure $2 \mathrm{C}$ and D. A fitting of the Fe2p peak is not possible. Figure 2C clarifies that iron could be detected on the steel surface of polymer-steel composite samples (side B).

The C1s spectrum, which exhibits an asymmetric peak shape could be fitted very well with six different peaks at binding energies of $284.8 \mathrm{eV}\left(\mathrm{C}_{1}\right), 285.3 \mathrm{eV}\left(\mathrm{C}_{2}\right), 286.5 \mathrm{eV}\left(\mathrm{C}_{3}\right)$, $290.8 \mathrm{eV}\left(\mathrm{C}_{4}\right), 291.6 \mathrm{eV}, 292.8 \mathrm{eV}\left(\mathrm{C}_{5,6}\right)$, and $288.5 \mathrm{eV}\left(\mathrm{C}^{\star}\right)$. 

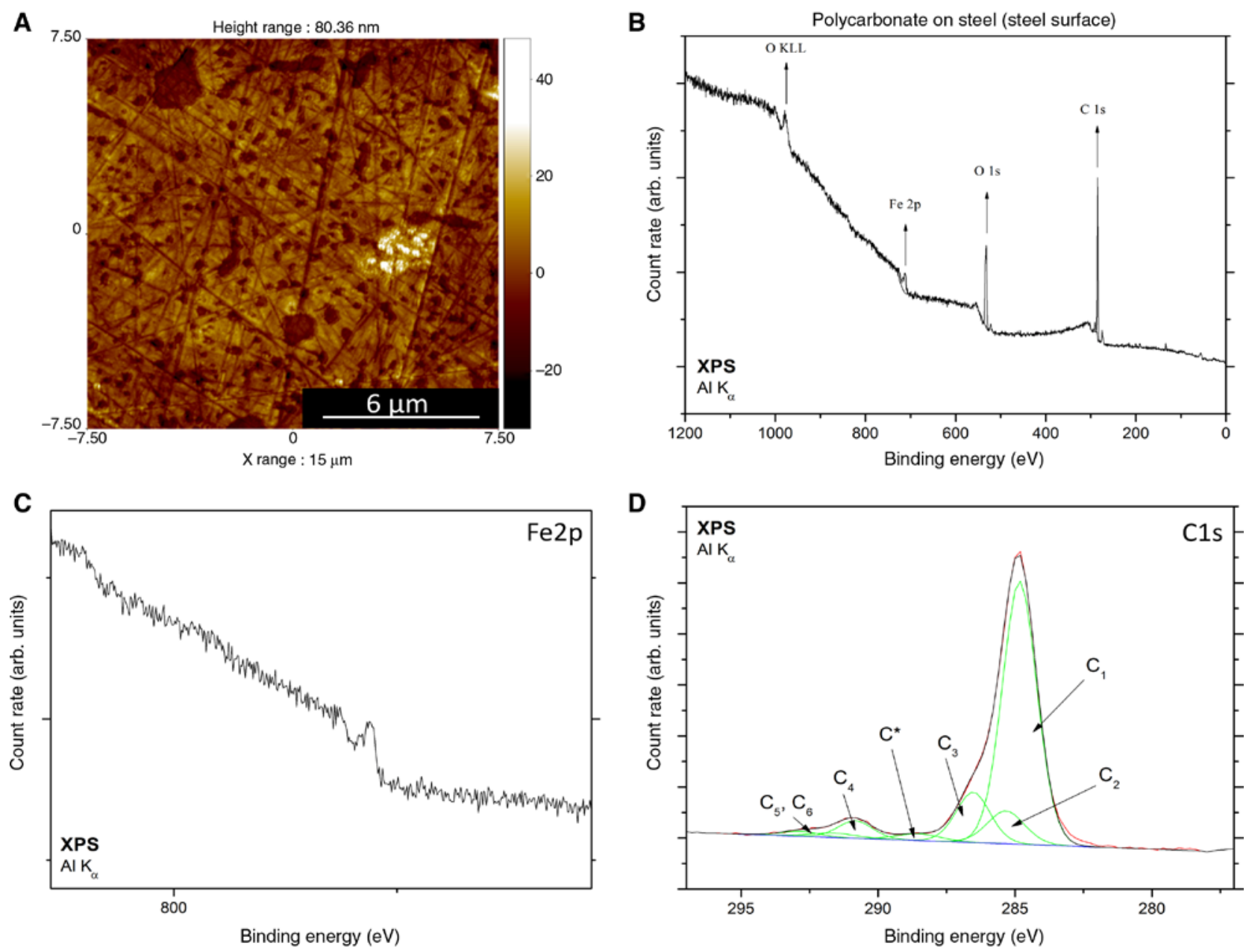

Figure 2: Microscopic and spectroscopic evidence for a very thin PC layer on sample side B. AFM image (A), survey spectrum (B), Fe2p XPS spectrum (C), and C1s spectrum (D) of the steel surface of polymer-steel composite sample (side B).

The peaks $\mathrm{C}_{1}-\mathrm{C}_{4}$ and $\mathrm{C}^{\star}$ can be assigned to $[19,20]$ :

$\left(\mathrm{C}_{1}\right)$ aromatic carbon

$\left(\mathrm{C}_{2}\right)$ aliphatic carbon

$\left(\mathrm{C}_{3}\right) \mathrm{C}_{\text {aromatic }}-\mathrm{O}$

$\left(\mathrm{C}_{4}\right) \mathrm{O}-\mathrm{C}(=\mathrm{O})-\mathrm{O}$

$\left(\mathrm{C}^{\star}\right) \mathrm{O}-\mathrm{C}=\mathrm{O}$

The chemical structure of polycarbonate is shown in Figure 3 and clarifies the allocation of carbon atoms. The two features of $\mathrm{C}_{5,6}$ can be attributed to the $\pi-\pi^{\star}$ emission

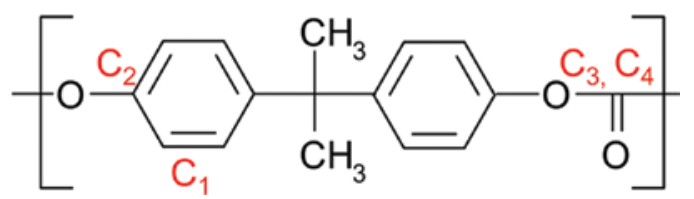

Figure 3: Chemical structure of polycarbonate. of aromatic carbon [19]. The $\pi-\pi^{\star}$ transition occurs as a result of excitation with X-rays during the measuring process. The binding energies and peak assignments are summarized in Table 1. Except for $\mathrm{C}^{\star}$, all peaks can be clearly assigned to the chemical bonds in the polycarbonate. In this regard, especially peak $\mathrm{C}_{4}(\mathrm{O}-\mathrm{C}(=\mathrm{O})-\mathrm{O})$, which is significant for this kind of polymer, can be unambiguously attributed to polycarbonate. Moreover, the peak proportions, which are shown in Table 1, are also in accordance with the chemical composition of the polymer. As the overall composition of the surface mainly shows carbon and oxygen, we conclude that the porous film primarily consists of polycarbonate. The existence of peak $C^{\star}(O-C=0)$ as well as the small deviations in the peak proportions compared to the theoretical values, however, may indicate that some of the monomeric units of the polymer are chemically modified. Such degradation effects might be a result of chain scission. 
Table 1: Binding energy and peak assignment of the C1s species measured by XPS.

\begin{tabular}{llllllll}
\hline Component & $\mathrm{C}_{1}$ & $\mathrm{C}_{2}$ & $\mathrm{C}_{3}$ & $\mathrm{C}_{4}$ & $\mathrm{C}_{5}$ & $\mathrm{C}_{6}$ & $\mathrm{C}^{*}$ \\
\hline Binding energy/eV & 284.8 & 285.3 & 286.5 & 290.8 & 291.6 & 292.8 & 288.5 \\
Assignment & Aromatic carbon & Aliphatic carbon & $\mathrm{C}_{\text {aromatic }}-0$ & $0-\mathrm{C}(=0)-0$ & $\pi-\pi^{\star}$ & $\pi-\pi^{\star}$ & $0-\mathrm{C}=0$ \\
Proportion (measured) & 68 & 9 & 13 & 5 & 2 & 1 & 2 \\
Proportion (theory) & 62 & 19 & 13 & 6 & - & - & - \\
\hline
\end{tabular}

As described above, the mechanical separation of the polymer-steel composite samples mostly results in two distinct pieces. The results for side $\mathrm{A}$, containing almost the complete solidified polymer, are shown in Figure 4.

Figure 4A shows the AFM image. A plateau structure can be identified (bright roundish spot). Figure 4B shows the XPS survey spectrum. Carbon at $297.5 \mathrm{eV}(82 \%)$ and oxygen $(16 \%)$ at $544.5 \mathrm{eV}$ can be identified as the main components. In addition, again, a small amount of iron
(2\%) at a binding energy of $713 \mathrm{eV}$ can be identified on side A. This is very surprising because the polymer is about 5 -mm thick, and there is no chance of any contributions from the steel substrate in the XPS. The results for the XPS detail measurements of the iron and carbon are shown in Figure $4 \mathrm{C}$ and D. A fitting of the Fe2p peak is not possible. Figure $4 \mathrm{C}$ is shown to clarify that iron could be detected as well on the steel surface of the polymer-steel composite sample (side A). The C1s spectrum could not be fitted
A

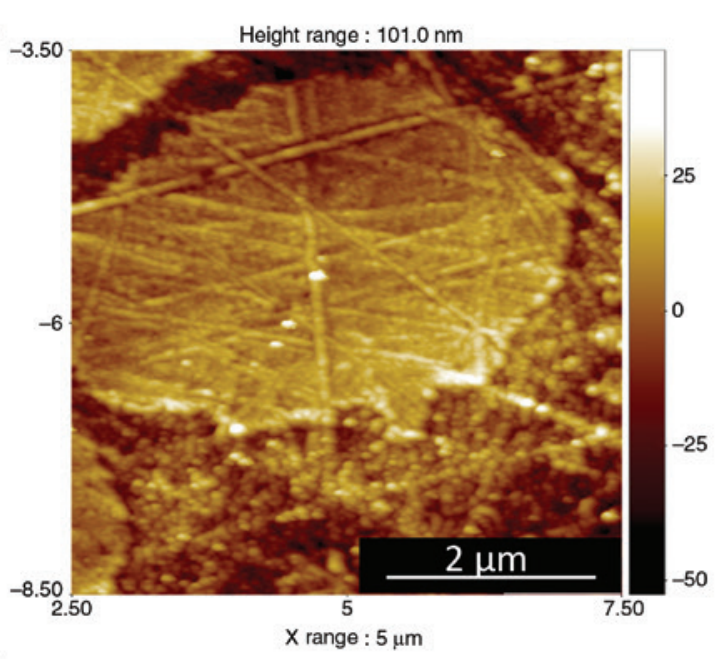

C

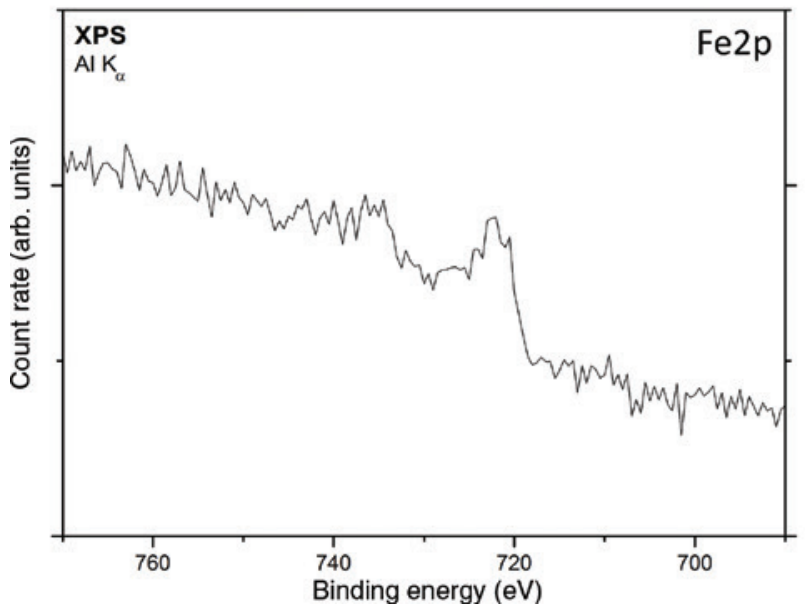

B

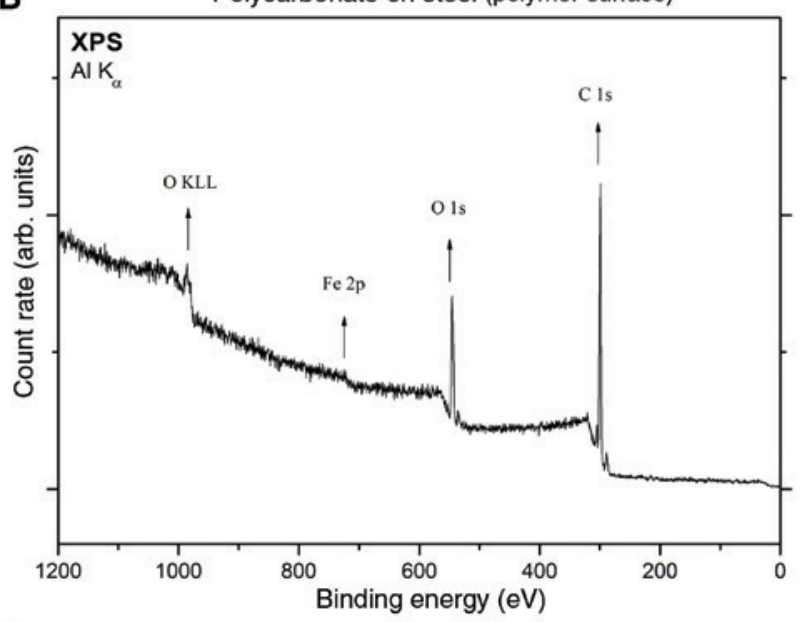

D

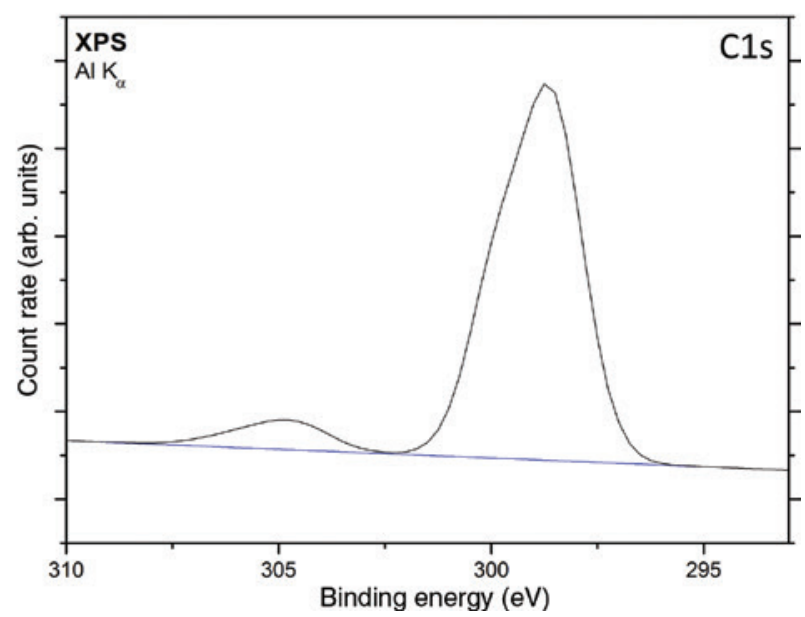

Figure 4: Microscopic and spectroscopic evidence for iron in the surface of the solidified polymer on sample side A. AFM image (A), survey spectrum (B), Fe2p XPS spectrum (C), and C1s XPS spectrum (D) of the solidified polymer surface of polymer-steel composite sample (side A). 
very well because of the thickness of the non-conductive polymer layer, which leads to charge effects and results in peak shifting and a broadening of the curve. Nevertheless, an intact polycarbonate layer is assumed.

Figure 5 shows the results for thin polymer films, which were prepared on $\mathrm{Fe}$ and $\mathrm{Cr}$ metal foils as described in the experimental section. The samples were heated up to $280^{\circ} \mathrm{C}$ for $120 \mathrm{~min}$, which is well below the polycarbonate degradation temperature of $450^{\circ} \mathrm{C}$ [21]. The metal/ polycarbonate interfaces were analyzed before and after heat treatment, respectively. The XPS spectra before and after heating as well as photographs of heated samples are shown in Figure 5.

The first column of Figure 5A, D, G shows light optical microscope pictures of the heated polycarbonate films on the three samples. On iron and steel, the surfaces show an intense blue color, while the chromium foil remains colorless. UV/Vis measurements of thin polymer films can be found in the supporting information. The second column of Figure 5B, E, H shows the XPS survey spectra of unheated polycarbonate layers on the substrates. The main peak in the spectra at a binding energy of 286.0 $\mathrm{eV}$ can be assigned to carbon. In addition, two more elements, oxygen and molybdenum, are detected at 532.5 $\mathrm{eV}$ and $233.0 \mathrm{eV}$. Oxygen and carbon can be assigned to polycarbonate. Molybdenum can be attributed to the sample holders, which were used for the XPS measurements. Chromium and iron were not detected at all, which means that the layer thickness must be at least $10 \mathrm{~nm}$ and that the polycarbonate layer is closed. The third column
A

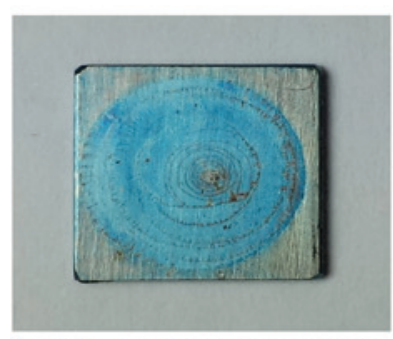

Polycarbonate layer on iron foil

D

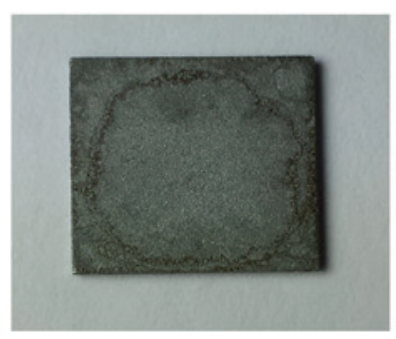

Polycarbonate layer on chromium foil

G

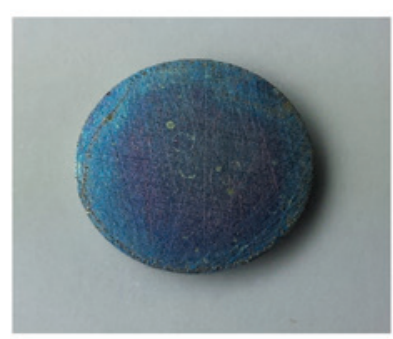

Polycarbonate layer on steel sample
B

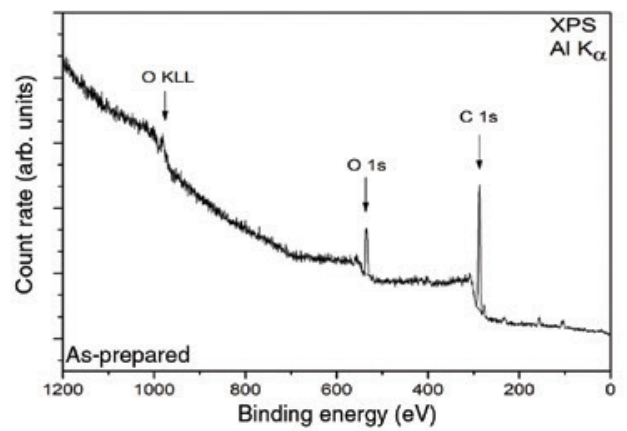

E

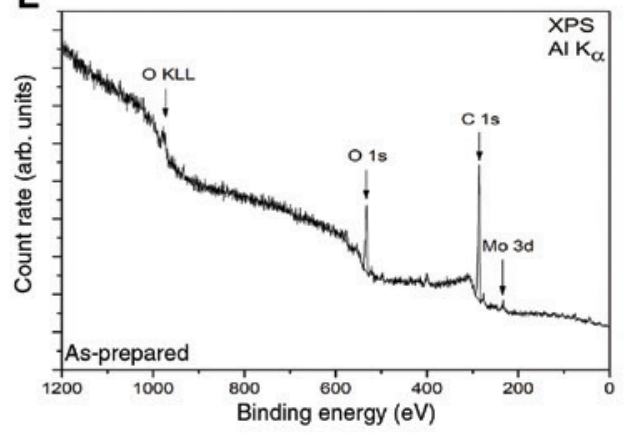

H

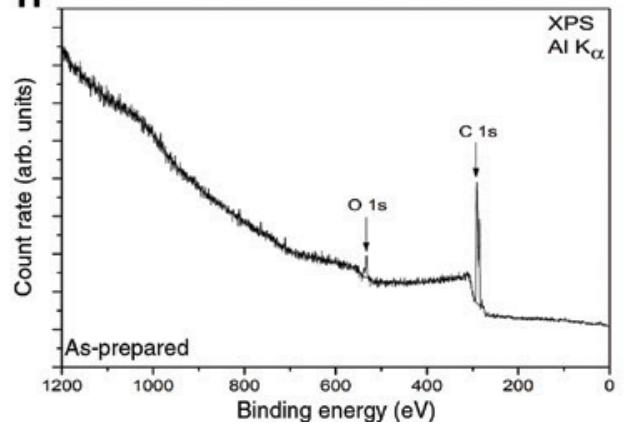

C

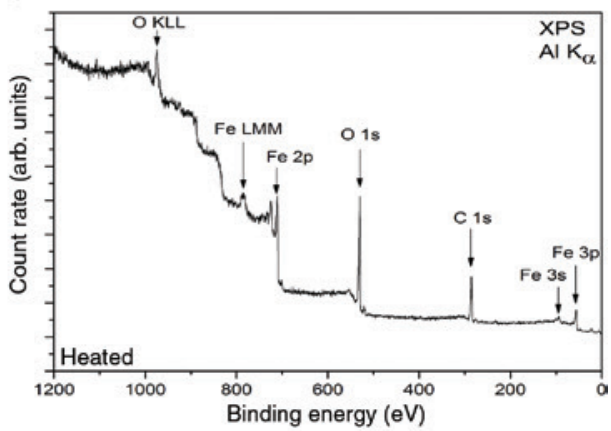

$F$

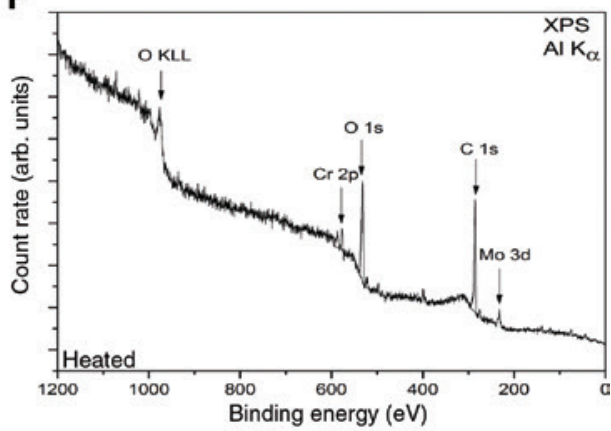

I

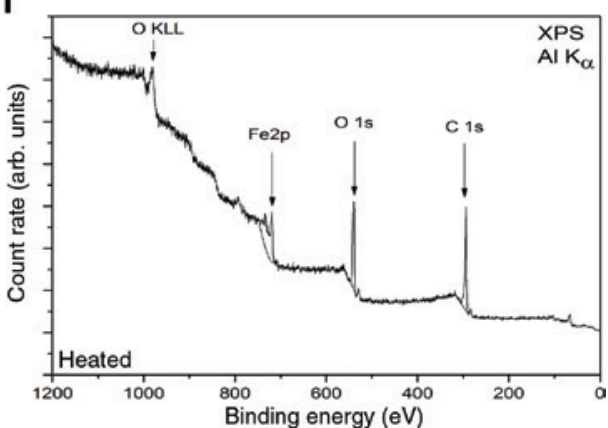

Figure 5: Spectroscopic prove of iron in cooperation into PC after heating. Light microscope pictures and XPS spectra of thin polymer films prepared on iron foil $(A-C)$, chromium foil (D-F), and tool steel specimen (G-I), before and after heating. 
of Figure 5C, F, I shows the XPS spectra after heating the samples. The top diagram of the third column (Figure 5C) shows the spectrum of the heated polymer layer on iron foil. The two peaks in the spectrum at $285.5 \mathrm{eV}$ and 530.0 $\mathrm{eV}$ can be attributed to carbon and oxygen. The peak at binding energy of $711.0 \mathrm{eV}$ can be assigned to iron. The amount of iron found after the heating procedure is about 19 at. $-\%$. The middle diagram of the third column (Figure 5F) shows the spectrum of heated polycarbonate layer on the chromium foil. Two peaks at $285.5 \mathrm{eV}$ and $532.5 \mathrm{eV}$ can again be assigned to carbon and oxygen, the peak at $233.0 \mathrm{eV}$ again to molybdenum. At $577.0 \mathrm{eV}$, a small chromium peak occurs. Before heating the sample, chromium was not detected. The amount of chromium found after heating is about 2 at. $\%$. The bottom diagram of the third column (Figure 5I) shows the XPS spectrum of the heated polycarbonate layer on tool steel specimen. Two peaks at binding energies of $285.0 \mathrm{eV}$ and $530.5 \mathrm{eV}$ can be assigned to carbon and oxygen. Besides this, at 711.0 $\mathrm{eV}$, a third peak, which can be attributed to iron, occurs. Figure 6 shows the SEM image and AES spectrum from the heated polycarbonate layer on the iron foil.

The examined sample surface from Figure 6 corresponds to the sample from Figure $5 \mathrm{~A}-\mathrm{C}$. Two different structures can be observed: (i) worm-like appearance (point 1), which corresponds to thicker layers of polycarbonate on the metal surface. Between the thicker layers, there are areas with thinner layers of polycarbonate. Clearly "crystalline" structures (measuring point 2) are also visible in these areas. The image shows clearly that the metal surface is completely covered with the polymer, although the thickness varies. AES was performed at the two marked points. The AES spectra are shown in
Figure 6B. Both spectra show the three characteristic peaks for the Fe LMM transition. The peaks are at kinetic energies of $598 \mathrm{eV}, 652 \mathrm{eV}$, and $705 \mathrm{eV}$. The AES results support the observation that iron diffuses into the polycarbonate layer during the heating process.

\section{Discussion}

All experiments on polymer-steel composites samples show that polymer films remain on both sample sides. Even side B, which appears optically to be free of polymer, shows thin and closed polymer films. Even more surprisingly, we also find iron on both sides of the separated composite samples.

The thin polymer films on the two different metal foils and the steel surface are colorless before heat treatment. However, after heating, the polycarbonate layers on the iron and steel surfaces turned intense blue. In contrast, the thin polymer film on chromium remains colorless and, therefore, appears to be unaltered. XPS furthermore shows small amounts of chromium besides iron. These observations prove that the diffusion of metal atoms from the steel surface into the polymer is occurring. Most likely, this is the basic process for all observations. Additionally, these results show that iron diffusion, but not chromium, most likely leads to a chemical modification of the polymer.

It is reported that thermal oxidation of polycarbonate may occur in the range $220^{\circ}-340^{\circ} \mathrm{C}$ [14]. Our samples were heated up to a maximum of $280^{\circ} \mathrm{C}$ for $2 \mathrm{~h}$. To check for any degradation effects, the samples were heated up to $360^{\circ} \mathrm{C}$ to estimate the influence of thermal oxidation. Only for temperatures beyond $360^{\circ} \mathrm{C}$ can a beginning yellowing of
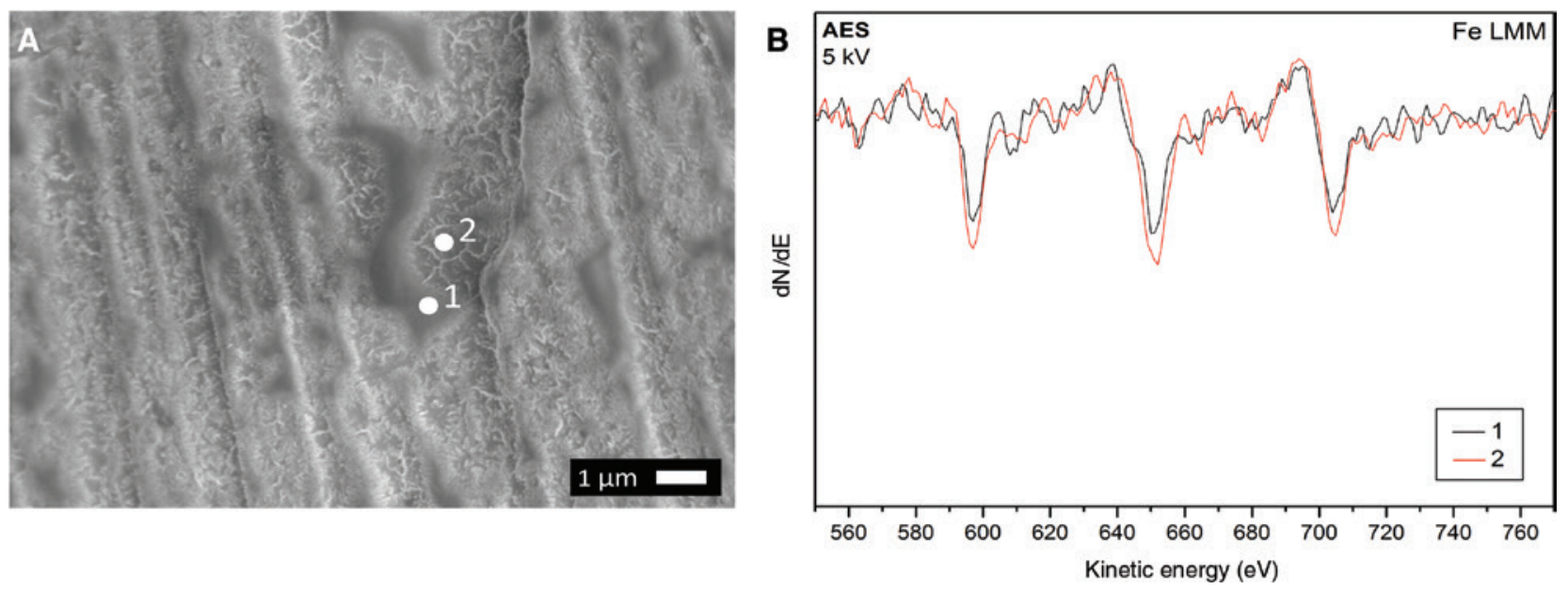

Figure 6: Microscopic and spectroscopic prove of iron in cooperation into PC after heating. SEM image (A) and AES spectrum (B) of thin polymer film prepared on iron foil after heating, corresponding to the sample in Figure $5 \mathrm{C}$. 
the sample surface be observed. Obviously, these samples were discolored as a result of the beginning degradation $[11,12,14,22]$. Our presented samples show a blue coloration. We do not observe any color change on chromium. Consequently, we conclude, that our samples are not influenced by any thermal degradation [14]. Furthermore, the polymer chains are immobilized, which is proven by an insolubility of the thin polymer layers. The diffused iron ions can form iron-polycarbonate complexes, which are chemically different from the pure polycarbonate. The agglomeration of such complexes via crosslinking most likely results in the formation of deposits. Insolubility may be due to this complexing reaction and crosslinking.

Figure 7 shows a model of the interface, which we propose on the basis of well-known processes.

The first step of the mechanism is the diffusion of iron ions through the top oxide layer into the polymer melt. The diffusion of metal ions into the polymer surface after metal evaporation was investigated by several working groups $[4,5,10]$. Metal ions in polymer layers after contact of a solid metal substrate with polymer melt could also be verified $[17,18]$. The diffusion length was up to $15 \mu \mathrm{m}$ [17]. Similar diffusion processes of iron and all other metals through oxide layers are well known, for example, from the atmospheric corrosion of steel [22]. The ambient atmosphere provides water layers on the surfaces in which atmospheric components are solved, for example, $\mathrm{SO}_{4}{ }^{2-}$ or $\mathrm{Cl}^{-}$ions. These ions introduce an image charge in the metal beneath the surface oxide layer when approaching the vicinity of the surface. Fe ions then diffuse through the top oxide layer driven by the image charge field [23]. Compared to the deposit formation process, polarized particles must be present at the surface [24]. Functional groups in the polycarbonate molecule (e.g. carbonyl group) or charged ions from additive molecules act as point charges in front of the steel surface. Because of the influence, image charges in the metal beneath the surface oxide layer are formed. This causes positively charged metal ions to diffuse through the oxide layer into the polymer melt.

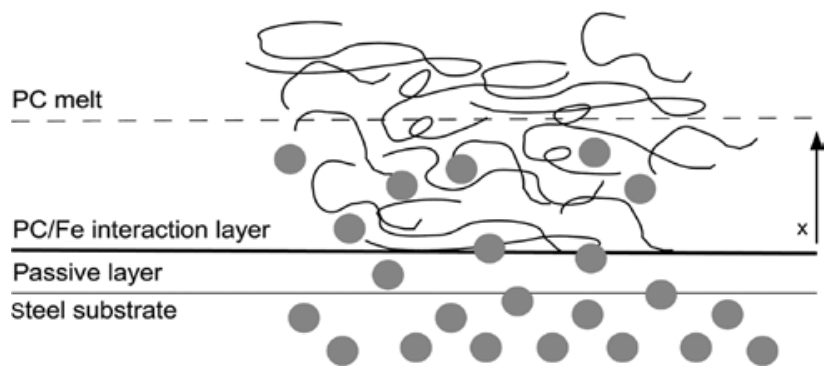

Figure 7: Sketch of the interface with diffusion of iron ions (gray) through the passive layer into the melt.
As a result of this diffusion process, iron ions penetrate into the polymer, obviously resulting in an interaction between the polymer chains and an immobilization of the chains. As described in the literature, there may be a preferred interaction between the carbonyl groups of the polycarbonate and the metal ions $[15,17]$.

These interactions result in the formation of plateouts along the steel surface. Metal diffusion and interaction is a major part of deposit formation in plastic processing.

\section{Summary}

The interfaces between polycarbonate and steel as well as the steel components iron and chromium were investigated. For this purpose, polymer-steel composite samples and thin polymer films on two different metal foils and the steel surface were prepared.

The diffusion of iron and chromium atoms from the steel surface into the polymer was verified by XPS. On iron and steel samples, thin polymer films show an intense blue coloration induced by an interaction between iron ions and polycarbonate. It is very probable that organic Fe complexes are formed. These complexes seem to be insoluble in solvents for polycarbonate and do not melt at processing temperatures of about $280^{\circ} \mathrm{C}$. Furthermore, the continuous agglomeration of such complexes probably leads to the observed spots in polycarbonate. Finally, no interaction between polycarbonate with chromium is observed.

Acknowledgments: The authors would like to thank Covestro AG for providing the polymer compound, Prof. W. Daum for providing the AFM and the SEM, and Prof. F. Endres for providing the XPS system. The IGF research project no. $18561 \mathrm{~N}$ of the Research Association Plastics (FGK) on "Mechanismen-basierte Strategien zur Vermeidung der Belagbildung in Kunststoffverarbeitungsmaschinen und Werkzeugen" was supported through the German Federation of Industrial Research Associations (AiF) within the frame of the Industrial Collective Research Program (IGF) by the Federal Ministry for Economic Affairs and Energy on the basis of a decision by the German Bundestag. This financial support is highly acknowledged. We furthermore extend our gratitude toward the members of the project support committee for their intensive support of the project work, Funder Id: http://dx.doi. org/10.13039/501100006360, Grant Number: IGF Research Project No. (18561 N). 
Conflict of interest statement: The authors declare to have no conflict of interests regarding this article.

\section{References}

[1] Bobzin K, Bagcivan N, Gillner A, Hartmann C, Holtkamp J, Michaeli W. Prod. Eng. Res. Devel. 2011, 5, 415-422.

[2] Bobzin K, Nickel R, Bagcivan N, Manz FD. Plasma Process. Polym. 2007, 4, 144-149.

[3] Bagcivan N, Bobzin K, Brögelmann T, Kalscheuer C. Surf. Coat. Technol. 2014, 260, 347-361.

[4] Faupel F, Willecke R, Thran A. Mater. Sci. Eng. Rep. 1998, 22, 1-55.

[5] Bechtolsheim CV, Zaporojtchenko V, Faupel F. J. Mater. Res. 1999, 14, 3538-3543.

[6] Burkstrand JM. Phys. Rev. B 1979, 12, 4853-4858.

[7] Burkstrand JM. Appl. Phys. Lett. 1978, 33, 387-389.

[8] Burkstrand JM. J. Appl. Phys. 1981, 52, 4795.

[9] Lee WJ, Lee YS, Rha SK, Lee YJ, Lim KY, Chung YD, Whang CN. Appl. Surf. Sci. 2003, 205, 128-136.

[10] Faupel F. Adv. Mater. 1990, 2, 266-268.

[11] Gupta MC, Viswanath SG. J. Therm. Anal. 1996, 46, 1671-1679.

[12] Blaszó M, Jakab E. J. Anal. Appl. Pyrolysis 1999, 49, 125-143.
[13] Friedrich JF, Unger WES, Lippitz A, Koprinarov I, Kühn G, Weidner S, Vogel L. Surf. Coat. Technol. 1999, 116, 772-782.

[14] Factor A. Angew. Makromol. Chemie 1995, 232, 27-43.

[15] Wiesing M, de los Arcos T, to Baben M, Rueß H, Schneider JM, Grundmeier G. Polym. Degrad. Stab. 2017, 143, 196-206.

[16] Gundjian M, Fisa B. J. Adhes. Sci. Technol. 1997, 6, 759-781.

[17] Kalnins M, Malers J. J. Adhes. 1997, 61, 175-194.

[18] Larrazabal HJ, Hrymak AN, Vlachopoulos J. Int. Polym. Process. 2006, 2, 132-140.

[19] Beamson G, Briggs D, Eds., High Resolution XPS of Organic Polymers: The Scienta ESCA300 Database, Wiley: Chichester, 1992.

[20] Muir BW, Mc Arthur SL, Thissen H, Simon GP, Griesser HJ, Castner DG. Surf. Interface Anal. 2006, 38, 1186-1197.

[21] Davis A, Golden JH. J. Macromol. Sci. Part C 2008, 3, 49-68.

[22] Chambers C, Holliday AK, Eds., Modern Inorganic Chemistry. An Intermediate Text, Butterworths: Oxford, 1975.

[23] Laygraf C, Graedel TE, Eds., Atmospheric Corrosion, 1st ed., John Wiley \& Sons: New York, 2000.

[24] He M, Lu TM, Eds., In Metal-Dielectric Interfaces in Gigascale Electronics, 1st ed., Springer Science \& Business Media: New York, 2012.

Supplementary Material: The online version of this article offers supplementary material (https://doi.org/10.1515/polyeng-2018-0324). 